\title{
Influence of small caliber coronary arteries on the diagnostic accuracy of adenosine stress cardiac magnetic resonance imaging
}

\author{
Günter Pilz • Tobias Heer • Maximilian Graw • \\ Eman Ali • Markus Klos • Roland Scheck • \\ Uwe Zeymer • Berthold Höfling
}

Received: 25 April 2010/Accepted: 7 September 2010/Published online: 24 September 2010

(C) The Author(s) 2010. This article is published with open access at Springerlink.com

\begin{abstract}
Background and aims Positive predictive value (PPV) of adenosine stress cardiac magnetic resonance (CMR) for coronary artery disease (CAD) is unsatisfactory. We investigated the impact of coronary caliber variability on this limitation in CMR performance.

Methods and results 206 consecutive patients with myocardial ischemia during CMR and subsequent coronary angiography (CA) were studied. Patients were examined in a 1.5-T scanner. After adenosine infusion, myocardial firstpass sequence using gadolinium-based contrast agent was performed and compared with rest perfusion. CAD was invasively confirmed in 165 [true positive (TP); PPV, $80.1 \%$ ] and ruled out in 41 patients [false positive (FP)]. TP and FP were comparable for pre-test risk and CMR findings. We found a significant association between FP CMR and the presence of a small caliber coronary vessel (proximal diameter $<$ one standard deviation below the mean) supplying the area of ischemia (chi-square 42.6, $p<0.0001$ ). A small caliber artery ipsilateral to the ischemic region was a predictive parameter for FP versus TP discrimination (ROC area, $0.84 \pm 0.04$ vs. $0.59 \pm 0.05 ; p<0.0001$ ).
\end{abstract}

G. Pilz ( $₫) \cdot$ T. Heer $\cdot$ M. Graw $\cdot$ E. Ali $\cdot$ M. Klos $\cdot$ B. Höfling Department of Cardiology, Clinic Agatharied, Academic Teaching Hospital, University of Munich, Norbert-Kerkel-Platz, 83734 Hausham, Germany

e-mail: pilz@khagatharied.de

R. Scheck

Department of Radiology, Clinic Agatharied, Academic Teaching Hospital, University of Munich,

Norbert-Kerkel-Platz, 83734 Hausham, Germany

T. Heer · U. Zeymer

Department of Cardiology, Heart Center Ludwigshafen,

Bremserstr. 79, 67063 Ludwigshafen, Germany
Further increment in diagnostic accuracy was achieved by including proximal ipsilateral/contralateral coronary diameter ratios (ROC area, $0.90 \pm 0.03 ; p<0.03$ ).

Conclusions Small caliber coronary arteries found as normal variations in right-dominant or left-dominant circulation may account for hypoperfusion in the absence of coronary stenosis and thus may cause FP adenosine stress CMR results. Non-invasive assessment of proximal coronary diameters in the vessel supplying the area of ischemia could reduce FP rates, raise the diagnostic accuracy of CMR for CAD and minimize subsequent superfluous CA.

Keywords Cardiac magnetic resonance imaging .

Adenosine stress - Myocardial perfusion .

Coronary artery disease $\cdot$ Coronary artery caliber

\section{Introduction}

Adenosine-stress cardiac magnetic resonance (CMR) imaging is increasingly proposed for non-invasive assessment of relevant coronary artery disease (CAD). Its high diagnostic sensitivity for the detection of significant CAD has been demonstrated in multiple studies [1-5]. Likewise, in patients with suspected CAD, normal adenosine stress CMR exams predict an excellent prognosis [6-8]. In contrast, the overall accuracy of adenosine stress perfusion CMR is presently limited by a lower specificity due to false positive (FP) results $[1,2]$, and the causes of this limitation are uncertain.

FP myocardial perfusion results have been correlated with variations in coronary anatomy for nuclear medicine single photon emission computed tomography (SPECT) imaging [9]. So far, little is known about the impact of the normal variability of coronary caliber and anatomy on the 
diagnostic performance of adenosine stress CMR. Aim of our study was to examine whether small caliber coronary arteries found as normal variations in right-dominant or left-dominant circulation may account for visualization of hypoperfusion in the absence of coronary stenosis and thus may result in FP results of CMR in the assessment of CAD.

\section{Methods}

\section{Study population}

From 5/2007 to 01/2008 we included 206 consecutive patients with suspected CAD and myocardial ischemia during adenosine-stress CMR (=positive CMR) who subsequently underwent coronary angiography (CA). According to the correlation of $\mathrm{CMR}$ and $\mathrm{CA}$, patients were classified as true-positive CMR (TP): positive CMR and relevant $\mathrm{CAD}$ in $\mathrm{CA}$ or false-positive $\mathrm{CMR}(\mathrm{FP})$ : positive $\mathrm{CMR}$ and no relevant CAD in CA.

Exclusion criteria were a history of myocardial infarction or a visualization of late gadolinium enhancement (LGE) in CMR. All anti-anginal medication and caffeine containing beverages were stopped $\geq 24 \mathrm{~h}$ before the CMR examination. Patients' pre-test risk was classified according to Morise et al. [10]. The study was carried out in compliance with the Declaration of Helsinki, and written informed consent was obtained from all patients. The protocol of study was approved by the local ethics committee.

\section{CMR examination}

CMR studies were performed with a 1.5-T magnetic resonance system (Signa Excite ${ }^{\circledR}$, GE Medical Systems, Milwaukee, USA) using a 8-element phased array surface coil (cardiac coil, GE Medical Systems). In case of claustrophobia a mild sedation with midazolam was offered. Cardiac function was assessed at rest in three long (twochamber, three-chamber and four-chamber) and contiguous short axes using steady-state free precession sequences.

After infusion of adenosine at a constant rate of $140 \mu \mathrm{g} /$ $\mathrm{kg}$ per minute over 3 min (Spectris MR injector, Medrad, Indianola, USA), first-pass kinetics of a gadolinium-based contrast agent (Gadodiamide, Omniscan ${ }^{\mathrm{TM}}$, GE Healthcare Buchler, Munich, Germany; $0.1 \mathrm{mmol} / \mathrm{kg}$ ) was measured during breath-hold in 4-5 contiguous short axis orientations at every heart beat using a hybrid gradient echo/echoplanar pulse sequence (echo time $1.2 \mathrm{~ms}$, flip angle $25^{\circ}$, slice thickness $8 \mathrm{~mm}$, field of view $32-34 \times 24-25.5 \mathrm{~cm}$, matrix $128 \times 96$ ) as previously described [8]. Ten minutes after stress perfusion a second perfusion study with the same setting was performed at rest. Ten minutes after this second bolus, LGE images were acquired using an inversion-recovery prepared gated fast-gradient echo-pulse sequence (repetition time $6.7 \mathrm{~ms}$; echo time $3.3 \mathrm{~ms}$; flip $20^{\circ}$; inversion time individually adjusted; slice thickness $8 \mathrm{~mm}$; rectangular field of view $30-34 \mathrm{~cm}$; matrix $256 \times 160)$. Again, 3 long and 4-5 short axes as planned in the perfusion study were acquired.

\section{CMR evaluation}

Two experienced investigators evaluated all CMR studies in consensus. Perfusion images were assessed visually. We compared stress to rest perfusion to reduce the potential rate of artefacts [11]. If a deficit was equally present at stress and rest, if it did not follow the subendocardial border, if ghosting artefacts could be seen or if it "blinked" bright and dark it was not regarded as an evident hypoperfusion, but a potential artefact. Such cases were not included into the study. As previously reported [8], a perfusion deficit was regarded as relevant if affecting $>1 / 3$ of myocardial wall thickness in $\geq 2$ neighboring segments (classified according to AHA recommendations [12]) and persisting $>5$ heart beats after maximal signal intensity in the cavity of the left ventricle (LV). Patients with a lesser degree of hypoperfusion were not included. The following parameters were measured: LV ejection fraction (\%), LV diastolic volume $(\mathrm{ml}), \mathrm{LV}$ mass $(\mathrm{g}), \mathrm{LV}$ wall stress $\left(\mathrm{N} / \mathrm{m}^{2}\right)$, transmural extent of ischemia $(\%)$, temporal persistence of ischemia (beats). For classification of TP versus FP CMR the area of maximal hypoperfusion was compared for presence or absence of stenosis in CA.

\section{Coronary angiography}

All patients underwent CA within $72 \mathrm{~h}$ after CMR examination. Significant CAD was defined as luminal narrowing of $\geq 70 \%$ in CA. Classification of dominance was done using the origin of the posterolateral branch as previously described [9, 13, 14]. If it was dominant and originating from the RCA, we classified the coronary tree as right-dominant, if it was dominant and originating from the LCX, we classified it as left-dominant, and if the coronary trees were equally supplied, we denoted the system balanced. Proximal diameters of LAD, LCX and RCA were assessed by quantitative coronary analysis (QCA). Diameters smaller than one standard deviation (SD) below the mean proximal coronary diameters in our study population were classified as "small caliber". This analysis was performed by the physician in charge with CA independently of CMR evaluation. Subsequently, ipsilateral/contralateral proximal coronary diameter ratios were calculated (vessel supplying the region of maximal hypoperfusion in CMR divided by the contralateral 
Table 1 Baseline patient characteristics

\begin{tabular}{lllll}
\hline & $\begin{array}{l}\text { All positive CMR } \\
\text { results }(n=206)\end{array}$ & $\begin{array}{l}\text { FP CMR results } \\
(n=41)\end{array}$ & $\begin{array}{l}\text { TP CMR results } \\
(n=165)\end{array}$ & $\begin{array}{l}p \text { value } \\
(\text { multivariate })\end{array}$ \\
\hline Age (years), mean \pm SD & $67.1 \pm 9$ & $62.5 \pm 11$ & $68.9 \pm 8$ & $<0.0001$ \\
Women (\%) & 43.9 & 75.6 & 32.5 & $15.5 \pm 3$ \\
Morise score (mean \pm SD) & $15.4 \pm 3$ & $15.0 \pm 3$ & 80.7 & 0.0001 \\
Systemic hypertension (\%) & 75.5 & 61.0 & 27.2 & 0.06 \\
Diabetes mellitus (\%) & 22.6 & 9.8 & 66.7 & 0.17 \\
Hypercholesterolemia (\%) & 60.6 & 43.9 & 42.1 & 0.27 \\
Smoker (\%) & 38.7 & 29.3 & 34.2 & 0.08 \\
Family history of CAD (\%) & 34.8 & 36.6 & $27.3 \pm 4$ & 0.24 \\
Body mass index $\left(\mathrm{kg} / \mathrm{m}^{2}\right)$ & $27.2 \pm 9$ & $26.8 \pm 4$ & & \\
\hline
\end{tabular}

territory coronary artery diameter: LCX/RCA, LAD/RCA or RCA/LCX, respectively).

\section{Statistical analysis}

Categorical variables are presented as percentage of incidence, continuous variables as mean \pm SD. Continuous variables were compared by analysis of variance. Association between groups was assessed by means of chi-square analysis. Relative contribution of the parameters for diagnostic accuracy was calculated by logistic regression analysis and receiver operating characteristic (ROC) curves were generated. Analyses were performed with commercially available statistic software (XLSTAT Version 2008.6.01, Addinsoft $^{\mathrm{TM}}$, Paris, France). For comparison for the areas under the ROC curves (AUC) we used Analyse-it ${ }^{\circledR}$ version 2.11, Analyse-it Software Ltd, Leeds, United Kingdom. A $p$ value $<0.05$ was considered statistically significant.

\section{Results}

Patient classification

Significant CAD was invasively confirmed in 165 (=TP CMR results) out of 206 patients [CMR positive predictive value (PPV), 80.1\%] and ruled out in 41 out of 206 patients with previous ischemia in magnetic resonance myocardial perfusion imaging (=FP CMR results). In the $17 \mathrm{FP}$ patients with other stress tests performed prior to CMR, 16 had also shown FP findings indicative of ischemia in these exams: 14 pathological stress electrocardiograms (ECG) and 2 pathological stress echocardiograms.

Baseline characteristics

The major clinical symptom was typical angina in $69.2 \%$ of the patients, exertional dyspnoea in $18 \%$ and arrhythmia with underlying cardiovascular risk profile in $12.8 \%$. Detailed patient characteristics and risk profile are given in Table 1. Patients with TP and with FP CMR results were comparable in their Morise risk scores. Patients with FP results were about 6 years younger than the TP ones and more often women (Table 1). Regarding systemic hypertension, diabetes mellitus, hypercholesterolemia and smoking, there was a trend towards higher incidence in the TP group. However, these differences did not reach statistical significance in a multivariate analysis approach.

Coronary dominance and coronary artery caliber

Coronary angiography confirmed that the proximal diameters of the coronary vessels correlated well with the type of coronary dominance (Fig. 1a). In balanced circulation, the proximal diameters of RCA, LCX and LAD were comparable. In right-dominant circulation, proximal RCA was significantly larger compared to LCX and LAD. In the cases of a left-dominant coronary tree, proximal RCA diameter was significantly smaller than the opposite larger proximal diameters of LCX and LAD.

Correlation of FP CMR results and coronary caliber

In comparison of TP and FP CMR results, we found significantly smaller sized mean proximal coronary artery diameters in the FP group (Fig. 1b). With a mean proximal coronary diameter of $3.5 \mathrm{~mm}$ and SD of $0.5 \mathrm{~mm}$, our criterion for classification of a vessel as small caliber was a proximal diameter of $<3.0 \mathrm{~mm}$. The presence of such a small caliber coronary vessel (mean proximal diameter $2.5 \pm 0.3 \mathrm{~mm}$ ) supplying the area of maximal ischemia in CMR, opposite to the dominant vessel, was encountered in $22 / 41(53.7 \%)$ of the FP cases. Compared to TP cases $[1 / 165(0.6 \%)]$, this incidence was significantly higher (chi-square 42.6, $p<0.0001$ ). FP ischemia territory was supplied in $17 / 22(77.3 \%)$ cases with right-dominant 
Fig. 1 Coronary artery diameters. Proximal diameters of the coronary vessels according to the type of coronary dominance (a) and to the validity $(T P$ or $F P$ ) of $C M R$ perfusion results $(\mathbf{b})$
Fig. 2 CMR and CA findings in a FP perfusion result. Inferoseptal ischemia (a) as FP perfusion CMR result in a patient without coronary artery stenoses but small caliber RCA (b) and left-dominant circulation (c)
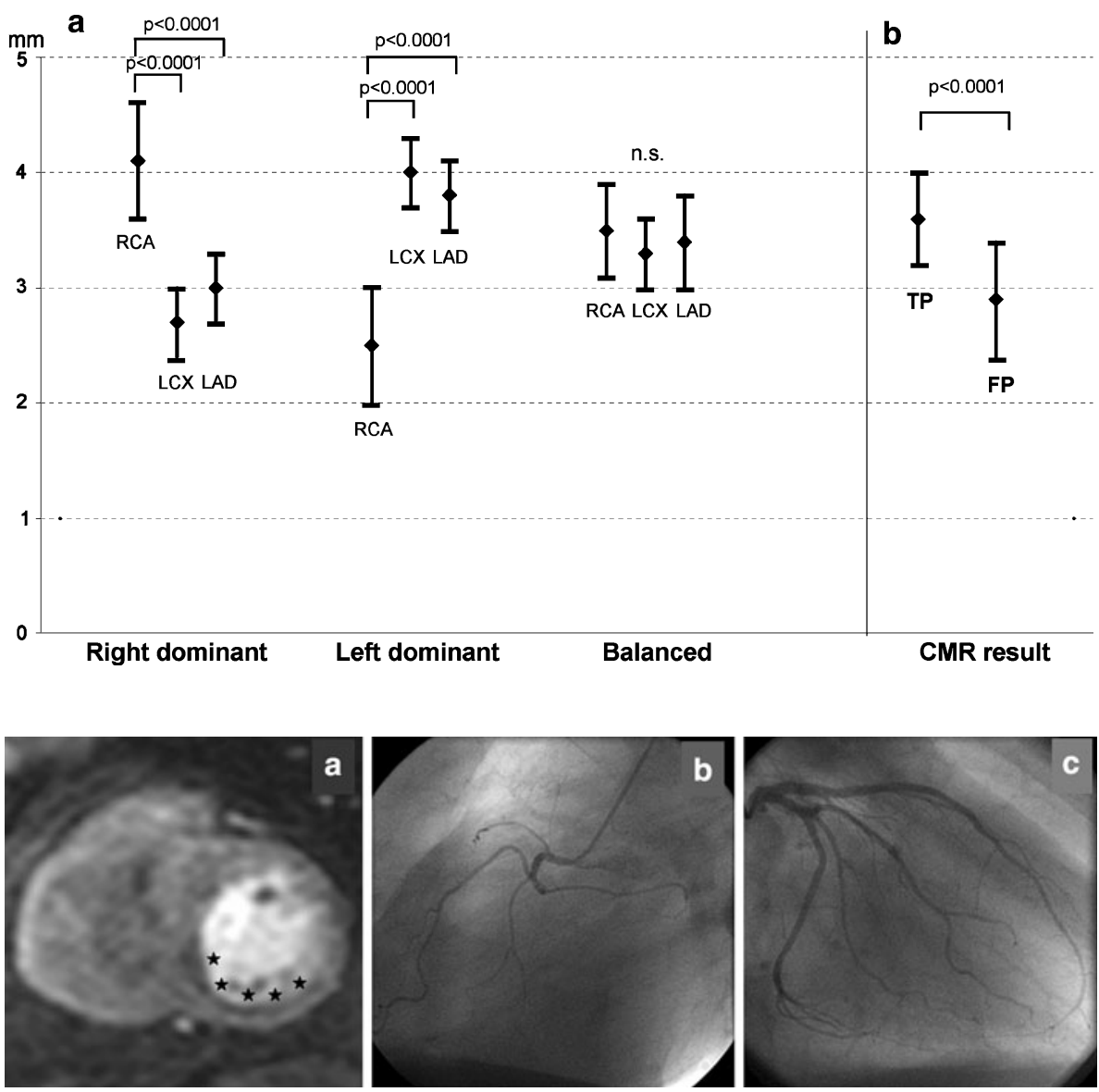

circulation by a small caliber LAD $(n=7)$ or LCX ( $n=10)$ and in $5 / 22(22.7 \%$ ) by the RCA in left-dominant circulation. Figure 2 shows an example of FP CMR with inferolateral ischemia in a patient with left-dominant circulation and small caliber RCA.

There was no difference between TP and FP patients regarding standard CMR findings (Table 2), which were not discriminatory between TP and FP (ROC curve area $0.58 \pm 0.05)$ ( $p=0.10$ vs. an AUC of 0.5; Fig. 3). In contrast, logistic regression analysis showed the presence of a small caliber vessel supplying the region of ischemia to be a highly predictive parameter for discrimination of FP versus TP $(p<0.0001)$. By adding this information to CMR, diagnostic ability to avoid FP improved significantly (ROC curve area $0.84 \pm 0.04, p<0.0001$ ). If the information on the presence of a small caliber coronary vessel supplying the area of maximal ischemia in CMR was included, PPV for CAD raised from 80.1 to $89.6 \%$. An additional increment in diagnostic accuracy was achieved by means of proximal ipsilateral/contralateral diameter ratios (AUC $0.90 \pm 0.03, p<0.03$; Fig. 3): a diameter ratio of $<0.82$ for the coronary vessel supplying the area of maximal ischemia in CMR correctly identified $53.7 \%$ of the FP results with a sensitivity of $99.4 \%$.
Table 2 CMR parameters in FP and TP perfusion results

\begin{tabular}{lllc}
\hline CMR parameter & $\begin{array}{l}\text { FP CMR results } \\
(n=41)\end{array}$ & $\begin{array}{l}\text { TP CMR results } \\
(n=165)\end{array}$ & $p$ value \\
\hline LV ejection fraction & $65.8 \% \pm 0.03$ & $65.6 \% \pm 0.09$ & 0.86 \\
LV enddiastolic volume $(\mathrm{ml})$ & $126 \pm 27$ & $129 \pm 31$ & 0.58 \\
LV mass (g) & $130 \pm 30$ & $137 \pm 37$ & 0.20 \\
LV wall stress $\left(\mathrm{N} / \mathrm{m}^{2}\right)$ & $35.7 \pm 5.5$ & $34.7 \pm 6.8$ & 0.62 \\
Transmural extent of ischemia & $41.1 \% \pm 6.8$ & $41.3 \% \pm 7.8$ & 0.64 \\
Temporal persistence of ischemia (beats) & $8.9 \pm 1.1$ & $8.7 \pm 1.0$ & 0.44 \\
CMR-CA correlation & & & $<0.0001$ \\
$\quad$ Ischemia in area with small caliber vessel & $53.7 \%$ & $0.9 \%$ & \\
\hline
\end{tabular}




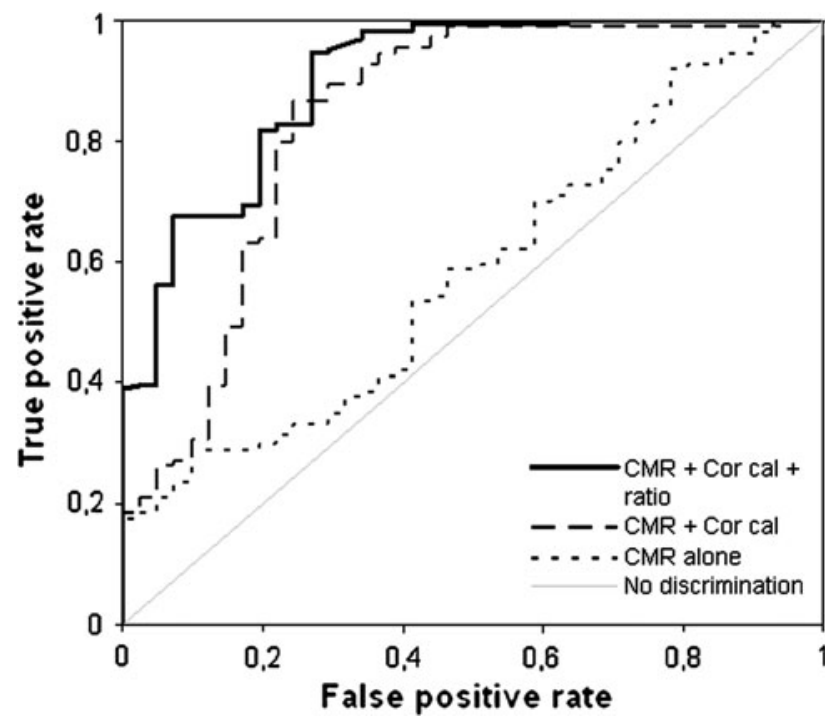

Fig. 3 Comparison of ROC curves for identification of FP patients. Standard CMR parameters alone (see Table 2) (dotted line) versus the combined approach of standard CMR parameters and proximal coronary caliber ( $\mathrm{Cor} \mathrm{cal}$ ) information [presence of a small caliber vessel in the area of ischemia (interrupted line), $p<0.0001]$ versus the combined approach of standard CMR parameters, proximal coronary caliber and ratios of ipsilateral/contralateral coronary diameter (full line, $p<0.03$ vs. CMR + Cor cal)

If adjusted for the disproportion of age and gender by means of matched pair analysis, these results were comparable (ROC curve areas: CMR alone $0.62 \pm 0.06$; CMR plus coronary caliber, $0.86 \pm 0.03 ; p<0.001$; plus diameter ratio, $0.91 \pm 0.04 ; p<0.05$ ).

For the 19 FP CMR cases with regular coronary caliber, none of the baseline and CMR parameters shown in Tables 1 and 2 allowed significant discrimination (all $p$ n.s.). The proportion of other pathological previous stress tests was similar in the small caliber $(9 / 22)$ and regular caliber (7/19) FP CMR subgroup ( $p=0.79)$.

Regardless of a FP or TP result, all patients with ischemia in the area supplied by a small caliber coronary artery were treated conservatively.

\section{Discussion}

Diagnostic performance of stress perfusion CMR for CAD evaluation is presently limited primarily by a lower specificity (FP results). In a large meta-analysis on 24 studies using perfusion CMR imaging mean specificity was $81 \%$. Our study on 206 consecutive patients yielded a PPV of $(80.1 \%)$, despite adding rest to stress perfusion imaging for recognition of artefacts as proposed by Thomson et al. [11]. Hence our population was representative for current CMR performance.

To the best of our knowledge, the present study is the first to describe an interrelationship between small caliber coronary vessels and CMR visualization of hypoperfusion in the absence of coronary stenosis (FP results regarding CAD). As the main finding of our study, we observed a correlation between FP CMR perfusion results and the presence of a small caliber coronary vessel supplying the area of ischemia in CMR, opposite to the dominant vessel. Of note, in the subgroup of patients with other stress tests performed prior to CMR these exams had similarly yielded pathological findings indicative of ischemia.

Our analysis showed the presence of such a small caliber vessel to be a possible predictive parameter for discrimination of false versus true positive. By adding this information to CMR perfusion, diagnostic performance improved by potentially avoiding up to half of FP CMR results. ROC curve analysis of a combined approach (CMR perfusion and proximal coronary diameter) yielded a significantly better result compared to CMR perfusion alone. This concept is strengthened by the further increment in CMR diagnostic accuracy achieved when additionally including the ratios of ipsilateral/contralateral coronary diameter for FP versus TP discrimination. In contrast, standard CMR function and perfusion criteria were not discriminatory (LV ejection fraction, LV enddiastolic volume, LV mass, LV wall stress, transmural extent of ischemia and temporal persistence of ischemia).

Anatomic studies have shown that while the irrigation of the sternocostal surface of the heart is extremely regular, the inferior or diaphragmatic surface supplied by the circumflex and right coronary arteries is highly variable and gives each heart its own "distinctive physiognomy" [15]. In this respect, the presence of small caliber coronary arteries has been described early. Concerning perfusion physiology, a study in healthy humans found heterogeneity of resting and hyperaemic myocardial blood flow with a broad range of regional distribution [16].

Although our description of an impact of small caliber coronary arteries for stress perfusion CMR evaluation may be considered disputable, the importance of coronary variability is well known in other cardiovascular imaging conditions. Most recently, Ortiz-Pérez et al. [17] have shown the impact of variations in coronary anatomy on the assignment of LGE viability assessment by CMR imaging to the specific coronary territory. Their study highlighted that in a per-segment analysis, only $76 \%$ of segments followed the distribution of coronary arteries empirically attributed and the discordance reached $67 \%$ of cases in a per-patient analysis. In the case of nuclear cardiac imaging, Segall et al. [9] concluded that the accurate assessment of coronary stenoses by thallium SPECT imaging requires close correlation with arteriography owing to the significant variability in normal coronary anatomy. A main finding of their study was the great variability in blood supply to the inferior and lateral wall, but also in the apex, 
which is one of the most variable regions with regard to myocardial perfusion [9]. The impact of coronary variability on ECG findings in acute myocardial infarction was first analyzed by Birnbaum et al. Thus, the occlusion in the same site of a coronary artery in different patients may result in a different size and location of the ischemic area at risk and hence the ECG pattern may not be the same in all cases with similar coronary artery occlusion [18]. These findings were confirmed by means of direct CMR scar visualization (LGE) by Rovai et al. [19].

The coronary distribution and calibers found in our study are in accordance with the literature. Thus, proximal coronary artery calibers measured in our study are in the magnitude of previous studies [14]. Similarly, the higher incidence of right dominant pattern in our study confirms former data [15].

Given the increasing demand for non-invasive assessment of suspected coronary artery disease [20], a method with higher sensitivity and specificity compared to the present approaches is strongly needed. A recent study using myocardial perfusion scintigraphy showed that a noninvasive "gatekeeper" approach could make about half of catheterizations redundant [21]. Furthermore, even in highrisk groups substantial savings were possible, and the risk of overlooking patients with severe disease seemed negligible. Besides clinical relevance, the approach of an ischemia-guided selective catheterization has been shown to potentially contribute to saving increasing health expenses [22], as has been most recently confirmed also for CMR perfusion imaging [23].

As a valuable alternative to perfusion scintigraphy for non-invasive CAD detection, perfusion stress CMR currently has reached very high sensitivity values, but is still limited by a lack in specificity [1,2]. Our results suggest that the knowledge of proximal coronary diameter provides added diagnostic value and may increase PPV of perfusion CMR up to $90 \%$ without relevant loss of sensitivity. Our data provide preliminary support for an extended CMR algorithm in CAD by adding proximal coronary artery diameter information to the current standard approach of Klem et al. (combination of stress perfusion and LGE [24]). Applied as a non-invasive gatekeeper, such an extended CMR approach could further reduce FP CMR results, and consequently, the rate of superfluous diagnostic $\mathrm{CA}$. We are aware that the major limitation for implementation of this CMR concept into clinical routine is the fact that magnetic resonance CA (MRCA) to date is still experimental and inferior to coronary computed tomographic angiography (CCTA) [25, 26]. Thus, a most recent attempt to integrate MRCA and CMR perfusion imaging was not successful [27]. Summarized, the usefulness of this extended CMR approach for clinical practice is limited as long as the vessel caliber is not known at the time of CMR.
Currently, it is primarily CCTA that could be applied to achieve this goal, particularly if radiation concerns [28, 29] are addressed with development of techniques leading to significant reduction in CCTA radiation exposure [30, 31].

In our study, nearly half of the FP CMR patients showed no association with coronary caliber variations. The reasons for these FP results were not identifiable either by standard CMR parameters, or by knowledge of the proximal diameters. Possible explanations are hypoperfusion due to variations in regional blood flow distribution [16] or to severe small vessel disease, a known cause of FP CMR results $[32,33]$. In addition, the findings might have been caused by unrecognized susceptibility, motion, or ringing artefacts, difficult to distinguish from perfusion deficits despite use of rest perfusion images as in reference [11]. Recent work has shown that one possibility to minimize "dark rim artefacts" was using higher field strength and parallel imaging strategies [34, 35].

The following limitations need to be mentioned for our study. It represents a single center experience with retrospective analysis of prospectively obtained data. Most important, we are aware that the finding of an association between FP CMR results and coronary caliber variations does not prove causal relationship, particularly since we did not perform quantitative perfusion analysis or invasive flow measurements. However, the pathological findings indicative of ischemia encountered in other stress tests support the interpretation of hypoperfusion as a potential cause of the FP results and argue against pure CMR artefacts. Further, we acknowledge that our criterion for classification of a vessel as small caliber may be considered arbitrary. Yet, in the absence of well established definitions the use of the range lesser than one SD below the mean seems plausible. The inclusion criterion of a positive CMR may cause selection bias and thus our results may not reflect the incidence of small caliber coronary arteries in the general population. Finally, since coronary diameter was measured by invasive $\mathrm{CA}$, it remains to be shown whether non-invasive MRCA and CCTA can yield equal results. Thus, our single-center experience should presently be considered as hypothesisgenerating result requiring prospective multicenter verification of our findings and evaluation of MRCA's potential in this concept.

\section{Conclusion}

Small caliber coronary arteries found as normal variations in right-dominant or left-dominant circulation may account for visualization of hypoperfusion in the absence of coronary stenosis and thus may cause FP adenosine stress CMR results in the assessment of CAD. Additional non-invasive 
assessment of the proximal coronary diameter in the vessel supplying the area of ischemia could reduce the rate of FP CMR results and increase PPV for CAD. Our data provide preliminary support for an algorithm which adds information about proximal coronary calibers to stress perfusion CMR imaging to raise the diagnostic accuracy of CMR in the evaluation of $\mathrm{CAD}$ and to minimize subsequent superfluous diagnostic CA.

Conflict of interest The present study was carried out without external funding. G. Pilz discloses consultancy fees and research grants received from GE Healthcare for other clinical studies. The other authors have no competing interests to disclose.

Open Access This article is distributed under the terms of the Creative Commons Attribution Noncommercial License which permits any noncommercial use, distribution, and reproduction in any medium, provided the original author(s) and source are credited.

\section{References}

1. Nandalur KR, Dwamena BA, Choudhri AF, Nandalur MR, Carlos RC (2007) Diagnostic performance of stress cardiac magnetic resonance imaging in the detection of coronary artery disease-a meta-analysis. J Am Coll Cardiol 50:1343-1353

2. Schwitter J, Wacker CM, van Rossum AC, Lombardi M, Al-Saadi N, Ahlstrom H, Dill T, Larsson HBW, Flamm SD, Marquardt M, Johansson L (2008) MR-IMPACT: comparison of perfusion-cardiac magnetic resonance with single-photon emission computed tomography for the detection of coronary artery disease in a multicentre, multivendor, randomized trial. Eur Heart J 29:480-489

3. Doesch C, Seeger A, Hoevelborn T, Klumpp B, Fenchel M, Kramer U, Schönfisch B, Claussen CD, Gawaz M, Miller S, May AE (2008) Adenosine stress cardiac magnetic resonance imaging for the assessment of ischemic heart disease. Clin Res Cardiol 97:905-912

4. Pilz G, Eierle S, Heer T, Klos M, Ali E, Scheck R, Wild M, Bernhardt P, Hoefling B (2010) Negative predictive value of normal adenosine-stress cardiac MRI in the assessment of coronary artery disease and correlation with semiquantitative perfusion analysis. J Magn Reson Imaging 32:615-621

5. Merkle N, Wöhrle J, Nusser T, Grebe O, Spiess J, Torzewski J, Hombach V (2010) Diagnostic performance of magnetic resonance first pass perfusion imaging is equally potent in female compared to male patients with coronary artery disease. Clin Res Cardiol 99:21-28

6. Ingkanisorn WP, Kwong RY, Bohme NS, Geller NL, Rhoads KL, Dyke CK, Paterson DI, Syed MA, Aletras AH, Arai AE (2006) Prognosis of negative adenosine stress magnetic resonance in patients presenting to an emergency department with chest pain. J Am Coll Cardiol 47:1427-1432

7. Jahnke C, Nagel E, Gebker R, Kokocinski T, Kelle S, Manka R, Fleck E, Paetsch I (2007) Prognostic value of cardiac magnetic resonance stress tests: adenosine stress perfusion and dobutamine stress wall motion imaging. Circulation 115:1769-1776

8. Pilz G, Jeske A, Klos M, Ali E, Hoefling B, Scheck R, Bernhardt $P$ (2008) Prognostic value of normal adenosine-stress cardiac magnetic resonance imaging. Am J Cardiol 101:1408-1412

9. Segall GM, Atwood JE, Botvinick EH, Dae MW, Lucas JR (1995) Variability of normal coronary anatomy: implications for the interpretation of thallium SPECT myocardial perfusion images in single-vessel disease. J Nucl Med 36:944-951

10. Morise AP, Jalisi F (2003) Evaluation of pretest and exercise test scores to assess all-cause mortality in unselected patients presenting for exercise testing with symptoms of suspected coronary artery disease. J Am Coll Cardiol 42:842-850

11. Thomson LEJ, Fieno DS, Abidov A, Slomka PJ, Hachamovitch R, Saouaf R, Friedman JD, Berman DS (2007) Added value of rest to stress study for recognition of artifacts in perfusion cardiovascular magnetic resonance. J Cardiovasc Magn Reson 9:733-740

12. Cerqueria MD, Weissmann NJ, Dilsizian V, Jacobs AK, Kaul S, Laskey WK, Pennell DJ, Rumberger JA, Ryan T, Verani MS, American Heart Association Writing Group on Myocardial Segmentation, Registration for Cardiac Imaging (2002) Standardized myocardial segmentation and nomenclature for tomographic imaging of the heart: a statement for healthcare professionals from the Cardiac Imaging Committee of the Council on Clinical Cardiology of the American Heart Association. Circulation 105:539-542

13. Schlesinger MJ (1940) Relation of anatomic pattern to pathologic conditions of the coronary arteries. Arch Pathol 30:403-415

14. Vieweg WVR, Alpert JS, Hagan AD (1976) Caliber and distribution of normal coronary arterial anatomy. Catheter Cardiovasc Diagn 2:269-280

15. Villallonga JR (2003) Anatomical variations of the coronary arteries: the most frequent variations. Eur J Anat 7(Suppl 1): 29-41

16. Chareonthaitawee P, Kaufmann PA, Rimoldi O, Camici PG (2001) Heterogeneity of resting and hyperemic myocardial blood flow in healthy humans. Cardiovasc Res 50:151-161

17. Ortiz-Pérez JT, Rodríguez J, Meyers SN, Lee DC, Davidson C, Wu E (2008) Correspondence between the 17-segment model and coronary arterial anatomy using contrast-enhanced cardiac magnetic resonance imaging. J Am Coll Cardiol Imaging 1:282-293

18. Birnbaum Y, Drew BJ (2003) The electrocardiogram in ST elevation acute myocardial infarction: correlation with coronary anatomy and prognosis. Postgrad Med J 79:490-504

19. Rovai D, Di Bella G, Rossi G, Lombardi M, Aquaro GD, L'Abbate A, Pingitore A (2007) Q-wave prediction of myocardial infarct location, size and transmural extent at magnetic resonance imaging. Coron Artery Dis 18:381-389

20. Pilz G, Bernhardt P, Klos M, Ali E, Wild M, Höfling B (2006) Clinical implication of adenosine-stress cardiac magnetic resonance imaging as potential gatekeeper prior to invasive examination in patients with AHA/ACC class II indication for coronary angiography. Clin Res Cardiol 95:531-538

21. Høilund-Carlsen P, Johansen A, Christensen H, Vach W, Møldrup M, Bertram P, Veje A, Haghfelt T (2006) Potential impact of myocardial perfusion scintigraphy as gatekeeper for invasive examination and treatment in patients with stable angina pectoris: observational study without post-test referral bias. Eur Heart J 27:29-34

22. Shaw LJ, Hachamovitch R, Berman DS, Marwick TH, Lauer MS, Heller GV, Iskandrian AE, Kesler KL, Travian MI, Lewin HC, Hendel RC, Borges-Neto S, Miller DD (1999) The economic consequences of available diagnostic and prognostic strategies for the evaluation of stable angina patients: an observational assessment of the value of precatheterization ischemia. J Am Coll Cardiol 33:661-669

23. Pilz G, Patel PA, Fell U, Ladapo JA, Rizzo JA, Fang H, Gunnarsson C, Heer T, Hoefling B (2010) Adenosine-stress cardiac magnetic resonance imaging in suspected coronary artery disease: a net cost analysis and reimbursement implications. Int $\mathrm{J}$ Cardiovasc Imaging 26. doi:10.1007/s10554-010-9645-9 (Epub ahead of print) 
24. Klem I, Heitner JF, Heitner JF, Shah DJ, Sketch MH, Behar V, Weinsaft J, Cawley P, Parker M, Elliott M, Judd RM, Kim RJ (2006) Improved detection of coronary artery disease by stress perfusion cardiovascular magnetic resonance with the use of delayed enhancement infarction imaging. J Am Coll Cardiol 47:1630-1638

25. Pouleur A-C, de Waroux J-B, Kefer J, Pasquet A, Vanoverschelde J-L, Gerber BL (2008) Direct comparison of whole-heart navigator-gated magnetic resonance coronary angiography and 40- and 64-slice multidetector row computed tomography to detect the coronary artery stenosis in patients scheduled for conventional coronary angiography. Circ Cardiovasc Imaging $1: 114-121$

26. Bluemke DA, Achenbach S, Budoff M, Gerber TC, Gersh B, Hillis LD, Hundley WG, Manning WJ, Printz BF, Stuber M, Woodard PK (2008) Noninvasive coronary artery imaging magnetic resonance angiography and multidetector computed tomography angiography. A scientific statement from the American Heart Association Committee on Cardiovascular Imaging and Intervention of the Council on Cardiovascular Radiology and Intervention, and the Councils on Clinical Cardiology and Cardiovascular Disease in the Young. Circulation 118:586-606

27. Klein C, Gebker R, Kokocinski T, Dreysse S, Schnackenburg B, Fleck E, Nagel E (2008) Combined magnetic resonance coronary artery imaging, myocardial perfusion and late gadolinium enhancement in patients with suspected coronary artery disease. J Cardiovasc Magn Reson 10:45

28. Fazel R, Krumholz HM, Wang Y, Ross JS, Chen J, Ting HH, Shah ND, Nasir K, Einstein AJ, Nallamothu BK (2009) Exposure to low-dose ionizing radiation from medical imaging procedures. N Engl J Med 361:849-857

29. Lauer MS (2009) Elements of danger-the case of medical imaging. N Engl J Med 361:841-843

30. Pflederer T, Rudofsky L, Ropers D, Bachmann S, Marwan M, Daniel WG, Achenbach S (2009) Image quality in a low radiation exposure protocol for retrospectively ECG-gated coronary CT angiography. Am J Roentgenol 192:1045-1050

31. Achenbach S, Marwan M, Ropers D, Schepis T, Pflederer T, Anders K, Kuettner A, Daniel WG, Uder M, Lell MM (2010) Coronary computed tomography angiography with a consistent dose below $1 \mathrm{mSv}$ using prospectively electrocardiogramtriggered high-pitch spiral acquisition. Eur Heart J 31:340-346

32. Panting JR, Gatehouse PD, Yang GZ, Grothues F, Firmin DN, Collins P, Pennell DJ (2002) Abnormal subendocardial perfusion in cardiac syndrome $\mathrm{X}$ detected by cardiovascular magnetic resonance imaging. N Engl J Med 346:1948-1953

33. Pilz G, Klos M, Ali E, Hoefling B, Scheck R, Bernhardt P (2008) Angiographic correlations of patients with small vessel disease diagnosed by adenosine-stress cardiac magnetic resonance imaging. J Cardiovasc Magn Reson 10:8

34. Gutberlet M, Noeske R, Schwinge K, Freyhardt P, Felix R, Niendorf T (2006) Comprehensive cardiac magnetic resonance imaging at 3.0 Tesla. Feasibility and implications for clinical applications. Invest Radiol 41:154-167

35. Strach K, Meyer C, Thomas D, Naehle CP, Schmitz C, Litt H, Bernstein A, Cheng B, Schild H, Sommer T (2007) Highresolution myocardial perfusion imaging at $3 \mathrm{~T}$ : comparison to $1.5 \mathrm{~T}$ in healthy volunteers. Eur Radiol 17:1829-1835 